
8 Research Square
Preprints are preliminary reports that have not undergone peer review.
They should not be considered conclusive, used to inform clinical practice,
or referenced by the media as validated information.

\title{
Effect of types of placenta previa on maternal and neonatal outcomes: A 10- year retrospective cohort study
}

\section{Shilei Bi}

Third Affiliated Hospital of Guangzhou Medical College

Lizi Zhang

Southern Medical University Nanfang Hospital

Zhijian Wang

Southern Medical University Nanfang Hospital

Jingsi Chen

Third Affiliated Hospital of Guangzhou Medical College

\section{Jingman Tang}

Third Affiliated Hospital of Guangzhou Medical College

\section{Jingjin Gong}

Third Affiliated Hospital of Guangzhou Medical College

\section{Sushan Xie}

Third Affiliated Hospital of Guangzhou Medical College

Hu Tan

Third Affiliated Hospital of Guangzhou Medical College

Lin Lin

Third Affiliated Hospital of Guangzhou Medical College

Luwen Ren

Third Affiliated Hospital of Guangzhou Medical College

Shanshan Zeng

Third Affiliated Hospital of Guangzhou Medical College

Lijun Huang

Third Affiliated Hospital of Guangzhou Medical College

Shaoshuai Wang ( $\nabla$ colombo2008@sina.com)

Tongji Hospital of Tongji Medical College of Huazhong University of Science and Technology

Lili Du ( $\square$ lilidu8107@hotmail.com )

Third Affiliated Hospital of Guangzhou Medical College

Dunjin Chen ( $\nabla$ gzdrchen@gzhmu.edu.cn )

Third Affiliated Hospital of Guangzhou Medical College

\section{Research Article}

Keywords: previa placenta, classification, ultrasound, maternal outcome, neonatal outcome

Posted Date: April 13th, 2021

DOI: https://doi.org/10.21203/rs.3.rs-17936/v2

License: @ (i) This work is licensed under a Creative Commons Attribution 4.0 International License. Read Full License 


\section{Abstract}

Purpose: Through this study, we aimed to evaluate the effects of different types of placenta previa (PP) on maternal and neonatal outcomes.

Methods: This study was conducted in The Third Affiliated Hospital of Guangzhou Medical University and Tongji Hospital between January 2009 and 2019. PP was traditionally classified into four types, namely low-lying placenta, marginal, partial, and complete PP. Previous studies have classified PP into two types, namely low-lying placenta and PP. Based on our clinical experience, we proposed the classification of PP into three types, for the first time, which included low-lying placenta, "marpartial" (marginal and partial) PP, and complete PP. Multivariate logistic regression analysis was performed to determine the effects of different types of PP on maternal and neonatal outcomes.

Results: In total, 4490 singleton pregnancies were complicated with PP. In the four-classification method, compared with women with low-lying placenta, women with complete PP had a risk of placenta accrete spectrum disorders, postpartum hemorrhage (PPH), hemorrhagic shock, severe PPH, blood transfusion, hysterectomy, puerperal infection, preterm labor, NICU admission, and low birth weight. There was no difference in maternal and neonatal outcomes between marginal and partial PP, except for increased chances of preterm labor and low birth weight in partial PP. In the two-classification method, PP was the risk factor for most of the adverse maternal and neonatal outcomes, compared with low-lying placenta.

Conclusion: Complete PP and low-lying placenta were associated with the highest and lowest risks of adverse pregnancy outcomes, respectively, whereas clinically similar outcomes were observed between marginal and partial PP. The three-classification of PP may be practical from the clinical perspective.

\section{Introduction}

The previously reported incidence of placenta previa (PP) was approximately 4.0 per 1000 births[1]. However, the incidence is increasing with the increasing rate of cesarean deliveries[2,3]. PP is a severe pregnancy complication that leads to life-threatening postpartum hemorrhage (PPH)[4], damages the surrounding organs, and endangers the lives of pregnant women[5]. The fetus may experience preterm delivery, or may have low birth weight or congenital defects[6,7]

PP is defined as the placenta overlying the endocervical os. The traditional classification of PP was complete PP (the placenta covers the internal os completely), partial PP (the placenta covers the internal os partially), marginal PP (the placental edge just reaches the margin of the internal os), and low-lying placenta (the placental edge is within $2 \mathrm{~cm}$ of the internal os)[8]. Advances in ultrasonography have enabled its use to evaluate suspected PP[9]. Currently, determining the location of the placenta using ultrasonography during mid-pregnancy is a routine practice[2].

Until recently, the traditional classification was used in clinical practice. The American Institute of Ultrasound in Medicine (AIUM) recommended eliminating the use of terms "partial" and "marginal," retaining the term "placenta previa"[10], as it is technically difficult to distinguish marginal and partial PP through ultrasound. In some studies[10] and guidelines[11], this two-classification method (low-lying placenta and placenta previa) was recommended. However, the traditional classification was still used in clinics in China.

Several studies have reported that the type of PP influences clinicians' management decisions, and maternal and neonatal outcomes. Compared with women with incomplete PP (including marginal and partial PP)[12,13], those with complete PP had a significantly higher frequency of PPH, hysterectomy, increased risk for placenta accrete, and more chances of preterm delivery. Dola et al. reported that compared with women with partial or marginal PP, those with complete PP experienced early onset of bleeding and antepartum hospitalization, and had a higher rate of hysterectomy. Women with partial and marginal PP did not show significant differences in this regard[14].

However, it is rational to revise the classification of PP from the clinical perspective. This study aimed to compare the maternal and neonatal outcomes in different types of PP and determine a better classification method of placenta previa in clinics.

\section{Materials And Methods}

\section{Study population}

This study was approved by the Research Ethics Board of The Third Affiliated Hospital of Guangzhou Medical University and Tongji Hospital, Tongji Medical College, Huazhong University of Science \& Technology. Written informed consent for participation was obtained from participants and their legally authorized representatives. This was a 10-year retrospective cohort study conducted from January 2009 to January 2019 in two tertiary hospitals (The Third Affiliated Hospital of Guangzhou Medical University, Guangzhou Medical Center for Critical Pregnant Women, Guangzhou; Tongji Hospital, Tongji Medical College, Huazhong University of Science \& Technology, Wuhan, China).

In this study, PP was diagnosed using the last transabdominal or transvaginal ultrasonography performed before delivery; if the placenta was located in the posterior wall of the uterus, transvaginal ultrasonography was preferred. All ultrasound examinations were performed by trained physicians instructed to record their best assessment of the distance from the leading placental edge to the internal cervix os, which was rounded to the nearest millimeter[15]. For pregnancies with gestational age more than 16 weeks, low-lying placenta was defined when the placental edge was less than $20 \mathrm{~mm}$ from the internal os[10], marginal PP was defined when the lower edge just reached the internal os, partial PP was defined when the placenta partially covered the cervix, and complete PP was defined when the placenta completely covered the cervix[2]. Sometimes, when the placenta was located in the posterior wall of uterus and the internal os was not obviously open, it was difficult to differentiate between marginal and partial PP. In such circumstances, three experienced examiners would perform the transvaginal ultrasound examination. The three sonographers agreed on the final diagnosis after discussion based on the ultrasound images. The position of the placenta, anterior or posterior, was also noted. 
Detailed data of 4490 pregnancies complicated with PP were recorded, including maternal age, gestational weeks, number of prior abortions, mode of delivery, requirement of cesarean section because of bleeding, mode of conception, level of education, smoking, drinking, mode of admission, type of PP, presence of diabetes mellitus or hypertension, and sex of the fetus.

In this study, we used different classification method of PP. The first one was the traditional four-classification method, including low-lying placenta, marginal, partial, and complete PP. The second one was the three-classification method, including low-lying placenta, "marpartial" (consisting of marginal and partial PP), and complete PP. The last one was the two-classification method according to AIUM, which included low-lying placenta and PP (consisting of marginal, partial, and complete PP).

\section{Maternal and neonatal outcomes}

Maternal outcome variables included placenta accrete spectrum (PAS) disorders, which consisted of placenta accreta, placenta increta, and placenta percreta diagnosed by surgeons or pathologists[16], postpartum hemorrhage (PPH [blood loss $\geq 500 \mathrm{~mL}$ during vaginal birth and $\geq 1000 \mathrm{~mL}$ during cesarean section within $24 \mathrm{~h}$ of delivery]), severe PPH (blood loss $\geq 1500 \mathrm{~mL}$ within $24 \mathrm{~h}$ of delivery), hemorrhagic shock[17], blood transfusion, hysterectomy, puerperal infection (including endometritis, mastitis, and wound infections), uterine rupture and bladder rupture caused by cesarean section, admission to the intensive care unit (ICU), hospital stay, and maternal death. Neonatal outcome variables included preterm labor (defined as delivery before 37 weeks of gestation), Apgar scores at 1 and $5 \mathrm{~min}$, admission to neonatal intensive care unit (NICU), birth weight $<2500 \mathrm{~g}$, and stillbirth (fetal death in the uterus after 20 weeks of gestation, including during childbirth).

\section{Statistics}

Statistical analysis was performed using SPSS v25.0 for Mac. Categorical variables were reported as frequency (percentage), and the differences between the groups were compared using the $\chi^{2}$ test, or Fisher exact test in cases of small numbers, as appropriate. Multivariate logistic regression analysis was performed to determine the role of the type of PP in adverse maternal and neonatal outcomes. Adjusted odds ratios (aORs), along with their $95 \%$ confidence intervals (Cls), were calculated. Potential confounders considered were maternal age; gestational age; prior number of cesarean sections, abortions, and vaginal deliveries; level of education; mode of delivery; and location of placenta[1,18]. Differences with $P$-values $<0.05$ were considered statistically significant.

\section{Results}

Out of the 4490 pregnant women recruited in this study, 2117 were from The Third Affiliated Hospital of Guangzhou Medical University, and the other 2373 were from Tongji Hospital, Tongji Medical College, Huazhong University of Science \& Technology. In total, 466, 1233, 140, and 2651 women had low-lying placenta, marginal, partial, and complete PP. The incidence of low-lying placenta, marginal, partial, and complete PP was 5\%, 31\%, 4\%, and $60 \%$ in Third Affiliated Hospital of Guangzhou Medical University and 16\%, 24\%, 2\%, and 58\% in Tongji Hospital, respectively (Fig. 1).

The general characteristics of women with PP as per the four-classification method are shown in Table 1 . Older women (aged $\geq 35$ years) were more likely to have complete PP, and their gestational age at delivery was 34-37 weeks. Meanwhile, the majority of women with low-lying placenta, marginal, and partial PP delivered at $\geq 37$ weeks of gestation $(76.2 \%, 56 \%$, and $45 \%$, respectively). The placental edge was lower and reached or even covered the cervix in women with more numbers of previous abortions, vaginal deliveries, or cesarean sections ( $\geq 2)(22.3 \%, 24.8 \%, 27.1 \%, 30.6 \% ; 1.3 \%, 2.4 \%, 3.6 \%, 3.6 \%$; and $2.1 \%, 3.5 \%, 6.4 \%$, and $6.8 \%$, in women with low-lying placenta, marginal, partial, and complete PP, respectively). The type of PP was found to be associated with educational level; more women with severe PP had not completed college education. Most pregnant women with low-lying placenta were undergoing treatment on an outpatient basis, whereas the majority of pregnant women with marginal, partial, or complete PP were admitted or transferred to the emergency department. More women with complete or partial PP than those with marginal PP or low-lying placenta underwent cesarean sections (99.3\%, $95.7 \%, 91 \%$, and $91.4 \%$, respectively). The general characteristics of women with PP as per the three-and two-classification methods are shown in Supplementary Tables 1 and 2 , respectively.

Tables 2 and 3 showed maternal and neonatal outcomes in different types of PP group compared with low-lying placenta group. When women with low-lying placenta was used as the reference group, both complete PP and placenta previa (including marginal, partial, and complete PP) were risk factors for PAS, PPH, severe PPH, hemorrhagic shock, blood transfusion, hysterectomy, and puerperal infection. Women with complete PP and PP required longer hospital stay and were more likely to require admission to the ICU. Complete PP and PP did not increase the risk of uterine rupture (Table 2).

Marginal, partial PP, and marpartial PP increased the risk of PPH and blood transfusion, compared with low-lying placenta. Compared with low-lying placenta, other types of PP increased the risks of preterm labor, admission to NICU, and low birth weight (Table 3).

Supplementary Tables 3 and 4 show maternal and neonatal outcomes in partial and complete PP groups, compared with the marginal PP group. When women with marginal PP were used as the reference group, the adverse maternal outcomes between women with marginal and partial PP were clinically similar. Complete PP was a risk factor for PAS, PPH, severe PPH, hemorrhagic shock, blood transfusion, hysterectomy, and admission to the ICU, compared with marginal PP (Supplementary Table 3). Compared with marginal PP, partial PP increased the risks of preterm delivery and low birth weight, and complete PP increased the risk of low 1-min and 5-min Apgar scores, preterm birth, and low birth weight (Supplementary Table 4).

Supplement Tables 5 and 6 show the maternal and neonatal outcomes in complete PP, compared with "marpartial” PP. Compared with "marpartial" PP, complete PP increased the risk of PAS, PPH, severe PPH, hemorrhagic shock, blood transfusion, hysterectomy, and admission to the ICU (Supplementary Table 5). In addition, complete PP increased the risk of low 1-min and 5-min Apgar scores, preterm, and low birth weight (Supplementary Table 6). 


\section{Discussion}

We collected the data of 4490 pregnancies complicated with PP in two tertiary hospitals from two different provinces, and we observed a high association between adverse pregnancy outcomes and the types of PP. According to the traditional classification method, we found that complete PP and low-lying placenta were the most and least dangerous types, respectively. Moreover, there was not much difference between marginal and partial PP with regard to their effects on maternal and perinatal outcomes (Supplementary Tables 3 and 4). We found that the effects of the four-classification method and threeclassification method of PP on maternal and neonatal outcomes were clinically similar (Tables 2 and 3 ). We also used the two-classification method from AIUM, which combined marginal, partial, and complete PP into PP. We found that PP increases the risk of PAS, PPH, hemorrhagic shock, severe PPH, blood transfusion, hysterectomy, puerperal infection, preterm labor, admission to NICU, and low birth weight (Tables 2 and 3). As per the two-classification method, PP conferred additional risks of marginal and partial PP on adverse pregnancy outcomes.

In line with our study, several studies have suggested that complete PP might be clinically different from incomplete PP, and that the former is associated with the highest risk of worsening maternal and perinatal complications[19,20]. Similar characteristics were observed between women with marginal and partial PP in the study by Dola et al., implying that they might be clinically similar to each other and different from complete PP[21]. However, Daskalakis et al. found that the type of PP did not influence the maternal and neonatal outcomes, except that neonates born to women with incomplete PP had lower Apgar scores than those of neonates born to women with complete PP[22]. Gorodeski and Bahari reported no difference between antepartum, intrapartum, or postpartum bleeding in different types of PP. They also noted that the gestational age, birth weight, and neonatal and perinatal mortality rates were similar among women with all types of PP[23].

In this study, the incidence of low-lying placenta, marginal, partial, and complete PP was $5 \%, 31 \%, 4 \%$, and $60 \%$ in Third Affiliated Hospital of Guangzhou Medical University and $16 \%, 24 \%, 2 \%$, and $58 \%$ in Tongji Hospital, respectively. Although the incidence rates of partial PP among the four types were the lowest, the composition ratios of different types of PP were similar in these two tertiary hospitals from two different provinces. The Third Affiliated Hospital of Guangzhou Medical University is the rescue center for major obstetric diseases in Guangdong Province. The proportion of relatively serious type of PP (marginal, partial, and complete PP) is higher than that in Tongji Hospital. In the study by Dola et al., a total of 179 patients had PP, out of whom 37 (21\%), 21 (12\%), and 117 (67\%) patients had marginal, partial, and complete PP, respectively[14]. The relationship between the edge of the placenta and cervical os might change as the gestational age progresses. In our study, the diagnosis of PP was based on the last ultrasound before delivery. We inferred that during late pregnancy, some partial PP might shift to milder type, especially when the cervix begins to dilate.

Initially, PP was distinguished by visual inspection or gentle palpation of the placental edge in a partly dilated cervix during labor[24]. With the application of ultrasound, especially transvaginal ultrasound, PP was diagnosed mainly by ultrasound rather than by palpation. Determining the location of the placenta using ultrasonography during mid-pregnancy was now a routine practice. However, it was technically difficult to differentiate between marginal and partial PP by ultrasound examination, especially as the opposite side of the internal cervical os could not be visualized on ultrasound[10]. Dashe et al.[25] reported an inability to precisely classify partial PP, especially in the absence of complete cervical dilation. Thus, it is debatable whether the traditional classification is currently practical.

In the present study, we found that as per traditional classification, compared with low-lying placenta, both marginal and partial PP increased the risk of PPH, blood transfusion, preterm labor, admission to NICU, and low neonatal birth weight. To further confirm that there was no clinical difference in the adverse pregnancy outcomes of women with marginal and partial PP, we considered women with marginal PP as the reference group (Supplementary Tables 3 and 4). We observed that partial PP did not increase the risk of other adverse pregnancy outcomes, except for increased risks of preterm labor and low neonatal birth weight. Owing to the technical difficulty of ultrasound in distinguishing marginal and partial PP, we proposed the three-classification method, which combines partial and marginal PP into one type, namely "marpartial" PP. As shown in Tables 2, 3, and Supplementary Tables 5 and 6, the three-classification method was clinically similar to the four-classification method in investigating the effect of different types of PP on adverse pregnancy outcomes.

According to the two-classification method, both marginal and partial PP afford risks of PAS, severe PPH, hemorrhagic shock, and hysterectomy, compared with low-lying placenta, however, this is not true (Table 2); only complete PP was the risk factor of those adverse pregnancy outcomes. Adopting this method would lead to wastage of medical resources, and would require more experienced clinicians, more blood, and more women would have to undergo hysterectomy. This could increase anxiety and tension among pregnant women, which is detrimental to good pregnancy outcomes. Hence, the threeclassification method is preferred to the two-classification method.

\section{Strengths and limitations}

Our study has several strengths. The relatively large sample size, including 4490 singleton pregnancies complicated with PP from two tertiary hospitals from two different provinces, enabled us to estimate the effect of different types of PP on adverse pregnancy outcomes. We first proposed the three-classification method to distinguish PP, and then used multivariate logistic regression analysis in three types of PP. Thus, the three-classification may be practical from the ultrasound and clinical perspective.

Nevertheless, our study has some limitations. This was a retrospective cohort; large and prospective studies in this regard are warranted. Just distinguishing the types of PP was insufficient for accurate prediction of adverse pregnancy outcomes.

\section{Conclusions}

Our results showed that complete PP was associated with the highest risk of adverse pregnancy outcomes. There was no clinical difference in maternal and neonatal outcomes between marginal and partial PP, except that partial PP had a greater risk of preterm labor and of delivering neonates with low birth 
weights. The three-classification method of PP (low-lying placenta, "marpartial," and complete PP) may be practical for use from the ultrasound and clinical perspective.

\section{Abbreviations}

PP: placenta previa; PAS: placenta accrete spectrum; PPH: postpartum hemorrhage; ICU: intensive care unit; NICU: neonatal intensive care unit; AIUM:

American Institute of Ultrasound in Medicine; Cl: confidence interval; aOR: adjusted odds ratios; ART: assisted reproductive technology; DM: diabetes mellitus

\section{Declarations}

\section{Acknowledgments}

This study was supported by grants from the National Key R\&D Program of China (No. 2016YFC1000405, 2017YFC1001402, 2018YFC1004104, and 2018YFC10029002) and the National Natural Science Foundation (No. 81830045, 81671533, 81971415, and 81571518).

\section{Funding}

This study was supported by grants from the National Key R\&D Program of China (No. 2016YFC1000405, 2017YFC1001402, 2018YFC1004104, and 2018YFC10029002) and the National Natural Science Foundation (No. 81830045, 81671533, 81971415, and 81571518). The funding sources had no influence on the content of the study.

\section{Conflicts of interest}

The authors declare that they have no conflicts of interest.

\section{Ethics approval and consent to participate}

This study was approved by the Research Ethics Board of the Third Affiliated Hospital of Guangzhou Medical University and Tongji Hospital, Tongji Medical College, Huazhong University of Science \& Technology.

\section{Consent for publication}

Not applicable

\section{Availability of data and material}

The datasets used and/or analyzed during the current study are available from the corresponding author on reasonable request.

\section{Code availability}

Not applicable

\section{Authors' contributions}

LZ, SB, and ZW contributed to the study design, data analysis, and manuscript writing and revision. JC, JT, JG, SX, and LL contributed to the data analysis and manuscript revision. LR, SZ, and LH contributed to data collection and management, SW, LD, and DC contributed to the manuscript revision and project development. All authors read and approved the final manuscript.

\section{References}

1. Faiz AS, Ananth CV(2003) Etiology and risk factors for placenta previa: an overview and meta-analysis of observational studies. J Matern Fetal Neonatal Med.13:175-90. doi: 10.1080/jmf.13.3.175.190.

2. Jauniaux E, Alfirevic Z, Bhide AG, Belfort MA, Burton GJ, Collins SL, Dornan S, Jurkovic D, Kayem G, Kingdom J, Silver R, Sentilhes L, Royal College of O, Gynaecologists (2019) Placenta Praevia and Placenta Accreta: Diagnosis and Management: Green-top Guideline No. 27a. BJOG 126: e1e48. doi:10.1111/1471-0528.15306

3. Roustaei Z, Vehvilainen-Julkunen K, Tuomainen TP, Lamminpaa R, Heinonen S (2018) The effect of advanced maternal age on maternal and neonatal outcomes of placenta previa: A register-based cohort study. Eur J Obstet Gynecol Reprod Biol 227:1-7. doi:10.1016/j.ejogrb.2018.05.025

4. Yu SCH, Cheng YKY, Tse WT, Sahota DS, Chung MY, Wong SSM, Chan OK, Leung TY (2020) Perioperative prophylactic internal iliac artery balloon occlusion in the prevention of postpartum hemorrhage in placenta previa: a randomized controlled trial. American Journal of Obstetrics \& Gynecology. doi:10.1016/j.ajog.2020.01.024

5. Baumfeld Y, Herskovitz R, Niv ZB, Mastrolia SA, Weintraub AY (2017) Placenta associated pregnancy complications in pregnancies complicated with placenta previa. Taiwanese Journal of Obstetrics and Gynecology 56 :331-335. doi:10.1016/j.tjog.2017.04.012

6. Tsuji M, Shibata E, Askew DJ, et al(2019) Associations between metal concentrations in whole blood and placenta previa and placenta accreta: the Japan Environment and Children's Study (JECS). Environ Health Prev Med. 24:40. doi:10.1186/s12199-019-0795-7 
7. Walfisch A, Beharier O, Shoham-Vardi I, Sergienko R, Landau D, Sheiner E (2016) Placenta previa and long-term morbidity of the term offspring. Eur J Obstet Gynecol Reprod Biol 203:1-4. doi:10.1016/j.ejogrb.2016.05.001

8. Oyelese Y, Smulian JC(2006) Placenta previa, placenta accreta, and vasa previa. Obstet Gynecol 107:927-41. doi: 10.1097/01.AOG.0000235893.09300.b7.

9. Garofalo A, Pilloni E, Alemanno MG, Garofalo G, Sciarrone A, Todros T, Viora E (2019) Ultrasound accuracy in prenatal diagnosis of abnormal placentation of posterior placenta previa. Eur J Obstet Gynecol Reprod Biol 242:86-91. doi:10.1016/j.ejogrb.2019.09.021

10. Reddy UM, Abuhamad AZ, Levine D, Saade GR, Fetal Imaging Workshop Invited P (2014) Fetal imaging: Executive summary of a Joint Eunice Kennedy Shriver National Institute of Child Health and Human Development, Society for Maternal-Fetal Medicine, American Institute of Ultrasound in Medicine, American College of Obstetricians and Gynecologists, American College of Radiology, Society for Pediatric Radiology, and Society of Radiologists in Ultrasound Fetal Imaging Workshop. Am J Obstet Gynecol 210:387-397. doi:10.1016/j.ajog.2014.02.028

11. Jauniaux E, Alfirevic Z, Bhide AG, Burton GJ, Collins SL, Silver R, Royal College of O, Gynaecologists (2019) Vasa Praevia: Diagnosis and Management: Green-top Guideline No. 27b. BJOG 126:e49-e61. doi:10.1111/1471-0528.15307

12. Tuzovic L(2006) Complete versus incomplete placenta previa and obstetric outcome. Int J Gynaecol Obstet 93:110-7. doi: 10.1016/j.ijgo.2006.02.006.

13. Baba Y, Takahashi H, Ohkuchi A, Usui R, Matsubara S (2016) Which type of placenta previa requires blood transfusion more frequently? A new concept of indiscernible edge total previa. The journal of obstetrics and gynaecology research 42:1502-1508. doi:10.1111/jog.13097

14. Chi P Dola, Thomas J Garite, David D Dowling,et al(2003) Placenta Previa: Does Its Type Affect Pregnancy Outcome? Am J Perinatol 20: 353-60. doi: $10.1055 / \mathrm{s}-2003-45282$

15. Quant HS, Friedman AM, Wang E, Parry S, Schwartz N (2014) Transabdominal ultrasonography as a screening test for second-trimester placenta previa. Obstet Gynecol 123:628-633. doi:10.1097/AOG.0000000000000129

16. Jauniaux E, Ayres-de-Campos D, Langhoff-Roos J, Fox KA, Collins S, Diagnosis FPA, Management Expert Consensus P (2019) FIGO classification for the clinical diagnosis of placenta accreta spectrum disorders. Int J Gynaecol Obstet 146:20-24. doi:10.1002/ijgo.12761

17. Lier H, Bernhard M, Hossfeld B(2018) Hypovolemic and hemorrhagic shock. Anaesthesist 67: 225-244. doi: 10.1007/s00101-018-0411-z.

18. Gluck O, Mizrachi Y, Bar J, Barda G (2018) The impact of advanced maternal age on the outcome of twin pregnancies. Arch Gynecol Obstet 297:891-895. doi:10.1007/s00404-018-4656-1

19. Yun Feng, Xue-Yin Li, Juan Xiao, et al(2018). Risk Factors and Pregnancy Outcomes: Complete Versus Incomplete Placenta Previa in Mid-pregnancy. Curr Med Sci 38: 597-601. doi: 10.1007/s11596-018-1919-9.

20. Ma L-k, Han N, Yang J-q, Bian X-m, Liu J-t (2012) Clinical Analysis of Placenta Previa Complicated with Previous Caesarean Section. Chinese Medical Sciences Journal 27:129-133. doi:10.1016/s1001-9294(14)60044-4

21. Tuzovic L (2006) Complete versus incomplete placenta previa and obstetric outcome. International journal of gynaecology and obstetrics: the official organ of the International Federation of Gynaecology and Obstetrics 93:110-117. doi:10.1016/j.ijgo.2006.02.006

22. Daskalakis G, Simou M, Zacharakis D, Detorakis S, Akrivos N, Papantoniou N, Fouskakis D, Antsaklis A (2011) Impact of placenta previa on obstetric outcome. International journal of gynaecology and obstetrics: the official organ of the International Federation of Gynaecology and Obstetrics 114:238241. doi:10.1016/j.ijgo.2011.03.012

23. Gorodeski IG, Bahari CM(1987) The effect of placenta previa localization upon maternal and fetal-neonatal outcome. J Perinat Med 15:169-77. doi: 10.1515/jpme.1987.15.2.169.

24. Oppenheimer LW, Farine D, Ritchie JWK, Lewinsky RM, Telford J, Fairbanks LA (1991) What is a low-lying placenta? American Journal of Obstetrics \& Gynecology 165:1036-1038. doi:10.1016/0002-9378(91)90465-4

25. Dashe JS, Mclntire Dd Fau - Ramus RM, Ramus Rm Fau - Santos-Ramos R, Santos-Ramos R Fau - Twickler DM, Twickler DM(2002) Persistence of placenta previa according to gestational age at ultrasound detection. Obstet Gynecol.99:692-7. doi: 10.1016/s0029-7844(02)01935-x.

\section{Tables}


Table 1

General characteristics of pregnant women with placenta previa as per four-classification method

\begin{tabular}{|c|c|c|c|c|c|}
\hline Variables & $\begin{array}{l}\text { Low-lying } \\
(n=466)\end{array}$ & $\begin{array}{l}\text { Marginal } \\
(n=1233)\end{array}$ & $\begin{array}{l}\text { Partial } \\
(n=140)\end{array}$ & $\begin{array}{l}\text { Complete } \\
(n=2651)\end{array}$ & $\mathbf{P}$ \\
\hline Age (y) & $31.54 \pm 4.94$ & $31.48 \pm 5.24$ & $30.49 \pm 5.04$ & $31.98 \pm 4.97$ & $<0.05$ \\
\hline$<35$ & $348(74.7 \%)$ & $872(70.7 \%)$ & $108(77.1 \%)$ & $1809(68.2 \%)$ & \\
\hline$\geq 35$ & $118(25.3 \%)$ & $361(29.3 \%)$ & $32(22.9 \%)$ & $842(31.8 \%)$ & \\
\hline Gestational age (wks) & $37.06 \pm 2.54$ & $36.14 \pm 2.79$ & $35.08 \pm 3.11$ & $35.91 \pm 2.43$ & $<0.05$ \\
\hline$<34$ & $47(10.1 \%)$ & $202(16.4 \%)$ & $39(27.9 \%)$ & $343(12.9 \%)$ & \\
\hline $34-37$ & $64(13.7 \%)$ & $340(27.6 \%)$ & $38(27.1 \%)$ & $1355(51.1 \%)$ & \\
\hline$\geq 37$ & $355(76.2 \%)$ & $691(56 \%)$ & $63(45 \%)$ & $953(35.9 \%)$ & \\
\hline Prior cesarean sections & $0.31 \pm 0.51$ & $0.34 \pm 0.55$ & $0.36 \pm 0.6$ & $0.57 \pm 0.63$ & $<0.05$ \\
\hline 0 & $330(70.8 \%)$ & 857 (69.5\%) & $99(70.7 \%)$ & $1334(50.3 \%)$ & \\
\hline 1 & $126(27 \%)$ & $333(27 \%)$ & $32(22.9 \%)$ & $1136(42.9 \%)$ & \\
\hline$\geq 2$ & $10(2.1 \%)$ & $434(3.5 \%)$ & $9(6.4 \%)$ & $181(6.8 \%)$ & \\
\hline Prior abortions & $0.83 \pm 1.06$ & $0.92 \pm 1.195$ & $0.93 \pm 1.104$ & $1.12 \pm 1.297$ & $<0.05$ \\
\hline 0 & $236(50.6 \%)$ & $600(48.7 \%)$ & $67(47.9 \%)$ & 1074 (40.5\%) & \\
\hline 1 & $126(27 \%)$ & $328(26.6 \%)$ & $35(25 \%)$ & $768(29 \%)$ & \\
\hline 2 & $104(22.3 \%)$ & $305(24.8 \%)$ & $38(27.1 \%)$ & $809(30.6 \%)$ & \\
\hline Prior deliveries & $0.17 \pm 0.42$ & $0.25 \pm 0.52$ & $0.28 \pm 0.52$ & $0.27 \pm 0.55$ & $<0.05$ \\
\hline 0 & $394(84.5 \%)$ & $965(78.3 \%)$ & $106(75.7 \%)$ & 2058 (77.6\%) & \\
\hline 1 & $66(14.2 \%)$ & $238(19.3 \%)$ & $29(20.7 \%)$ & $500(18.9 \%)$ & \\
\hline$\geq 2$ & $6(1.3 \%)$ & $30(2.4 \%)$ & $5(3.6 \%)$ & $93(3.6 \%)$ & \\
\hline Level of education & & & & & $<0.05$ \\
\hline Graduate & $266(57.1 \%)$ & $538(43.6 \%)$ & $59(42.1 \%)$ & $939(35.4 \%)$ & \\
\hline Undergraduate & $183(39.3 \%)$ & $663(53.8 \%)$ & $78(55.7 \%)$ & $1650(62.2 \%)$ & \\
\hline unknown & $17(3.6 \%)$ & $32(2.6 \%)$ & $3(2.1 \%)$ & $62(2.3 \%)$ & \\
\hline Mode of admission & & & & & $<0.05$ \\
\hline Clinic & $411(88.2 \%)$ & $895(72.6 \%)$ & $88(62.9 \%)$ & 1943 (73.3\%) & \\
\hline Emergency & $41(8.8 \%)$ & $225(18.2 \%)$ & $27(19.3 \%)$ & $374(14.1 \%)$ & \\
\hline Referral & $14(3 \%)$ & $113(9.2 \%)$ & $25(17.9 \%)$ & $334(12.6 \%)$ & \\
\hline Smoking & 0 & 2 & 0 & 3 & \\
\hline Drinking & 0 & 0 & 0 & 2 & \\
\hline ART & $48(10.3 \%)$ & $112(9.1 \%)$ & $15(10.7 \%)$ & $219(8.3 \%)$ & 0.386 \\
\hline DM & $75(16.1 \%)$ & $193(15.7 \%)$ & $13(9.3 \%)$ & $390(14.7 \%)$ & $<0.05$ \\
\hline Hypertensive disorders & $22(4.7 \%)$ & $58(4.7 \%)$ & $6(4.3 \%)$ & $58(2.2 \%)$ & $<0.05$ \\
\hline Cesarean & 426 (91.4\%) & 1122 (91\%) & 134 (95.7\%) & 2633 (99.3\%) & $<0.05$ \\
\hline Sex & & & & & 0.06 \\
\hline Male & $241(51.7 \%)$ & 708 (57.4\%) & $79(56.4 \%)$ & $241(51.7 \%)$ & \\
\hline Female & $222(47.6 \%)$ & $512(41.5 \%)$ & $60(42.9 \%)$ & $222(47.6 \%)$ & \\
\hline Unknown & $3(0.6 \%)$ & $13(1.1 \%)$ & $1(0.7 \%)$ & $3(0.6 \%)$ & \\
\hline
\end{tabular}


Table 2

Maternal outcomes as per four-classification method of placenta previa

\begin{tabular}{|c|c|c|c|c|c|c|c|c|c|c|c|}
\hline \multirow{3}{*}{$\begin{array}{l}\text { Variables } \\
\text { PAS }\end{array}$} & \multirow{3}{*}{$\begin{array}{l}\text { Low } \\
(n= \\
466)\end{array}$} & \multirow{3}{*}{$\begin{array}{l}\text { Marginal } \\
(n= \\
1233) \\
\\
308 \\
(25 \%)\end{array}$} & \multirow{3}{*}{$\begin{array}{l}\text { Partial } \\
(n= \\
140) \\
43 \\
(30.7 \%)\end{array}$} & \multirow{3}{*}{$\begin{array}{l}\text { Complete } \\
(\mathrm{n}= \\
2651) \\
\\
1438 \\
(54.2 \%)\end{array}$} & \multicolumn{6}{|c|}{ Low-lying as reference } & \multirow{3}{*}{$\begin{array}{r}\text { Mal } \\
\text { Lon } \\
0.95\end{array}$} \\
\hline & & & & & \multicolumn{2}{|c|}{$\begin{array}{l}\text { Marginal } \\
\text { aOR }\end{array}$} & \multicolumn{2}{|c|}{$\begin{array}{l}\text { Partial } \\
\text { aOR }\end{array}$} & \multicolumn{2}{|c|}{$\begin{array}{l}\text { Complete } \\
\text { aOR }\end{array}$} & \\
\hline & & & & & 1.04 & $0.8-1.36$ & 1.37 & $0.89-2.13$ & 3.12 & $2.46-3.97$ & \\
\hline $\mathrm{PPH}$ & $\begin{array}{l}39 \\
(8.4 \%)\end{array}$ & $\begin{array}{l}191 \\
(15.5 \%)\end{array}$ & $\begin{array}{l}28 \\
(20 \%)\end{array}$ & $\begin{array}{l}1175 \\
(44.3 \%)\end{array}$ & 1.84 & $1.27-2.67$ & 2.45 & $1.41-4.24$ & 7.11 & $5-10.09$ & 0.53 \\
\hline Severe PPH & $\begin{array}{l}8 \\
(1.7 \%)\end{array}$ & $37(3 \%)$ & $\begin{array}{l}5 \\
(3.6 \%)\end{array}$ & $\begin{array}{l}422 \\
(15.9 \%)\end{array}$ & 1.64 & $0.75-3.58$ & 1.84 & $0.58-5.86$ & 8.12 & $3.97-16.61$ & 0.6 \\
\hline Shock & $\begin{array}{l}20 \\
(4.3 \%)\end{array}$ & $\begin{array}{l}85 \\
(6.9 \%)\end{array}$ & $\begin{array}{l}10 \\
(7.1 \%)\end{array}$ & $\begin{array}{l}640 \\
(24.1 \%)\end{array}$ & 1.48 & $0.89-2.45$ & 1.46 & $0.66-3.23$ & 5.48 & $3.45-8.71$ & 0.66 \\
\hline $\begin{array}{l}\text { Blood } \\
\text { transfusion }\end{array}$ & $\begin{array}{l}27 \\
(5.8 \%)\end{array}$ & $\begin{array}{l}147 \\
(11.9 \%)\end{array}$ & $\begin{array}{l}24 \\
(17.1 \%)\end{array}$ & $\begin{array}{l}994 \\
(37.5 \%)\end{array}$ & 1.93 & $1.25-2.99$ & 2.67 & $1.45-4.92$ & 7.09 & $4.72-10.66$ & 0.51 \\
\hline $\begin{array}{l}\text { Bladder } \\
\text { rupture }\end{array}$ & 0 & $5(0.4 \%)$ & 0 & $\begin{array}{l}30 \\
(1.1 \%)\end{array}$ & & & & & & & \\
\hline $\begin{array}{l}\text { Uterine } \\
\text { rupture }\end{array}$ & $\begin{array}{l}4 \\
(0.9 \%)\end{array}$ & $5(0.4 \%)$ & $\begin{array}{l}2 \\
(1.4 \%)\end{array}$ & $\begin{array}{l}17 \\
(0.6 \%)\end{array}$ & 0.37 & $0.1-1.42$ & 1.23 & $0.22-6.92$ & 0.4 & $0.13-1.24$ & 2.74 \\
\hline Hysterectomy & $\begin{array}{l}3 \\
(0.6 \%)\end{array}$ & $\begin{array}{l}26 \\
(2.1 \%)\end{array}$ & $\begin{array}{l}2 \\
(1.4 \%)\end{array}$ & $\begin{array}{l}205 \\
(7.7 \%)\end{array}$ & 3 & $0.9-10$ & 1.79 & $0.29-10.99$ & 8.62 & $2.73-27.28$ & 0.33 \\
\hline $\begin{array}{l}\text { Puerperal } \\
\text { infection }\end{array}$ & $\begin{array}{l}4 \\
(0.9 \%)\end{array}$ & $\begin{array}{l}35 \\
(2.8 \%)\end{array}$ & $\begin{array}{l}2 \\
(1.4 \%)\end{array}$ & $\begin{array}{l}118 \\
(4.5 \%)\end{array}$ & 2.88 & $1.02-8.18$ & 1.19 & $0.22-6.65$ & 3.75 & $1.37-10.28$ & 0.34 \\
\hline ICU & 0 & $\begin{array}{l}18 \\
(1.5 \%)\end{array}$ & $\begin{array}{l}2 \\
(1.4 \%)\end{array}$ & $\begin{array}{l}149 \\
(5.6 \%)\end{array}$ & & & & & & & \\
\hline $\begin{array}{l}\text { Hospital stay } \\
\text { (d) }\end{array}$ & $\begin{array}{l}7.68 \pm \\
4.4\end{array}$ & $\begin{array}{l}8.75 \pm \\
5.31\end{array}$ & $\begin{array}{l}8.43 \pm \\
4.2\end{array}$ & $10.36 \pm 6$ & & & & & & & \\
\hline $\begin{array}{l}\text { Maternal } \\
\text { death }\end{array}$ & 0 & 0 & 0 & 1 & & & & & & & \\
\hline
\end{tabular}

Table 3

Perinatal outcomes as per four-classification method of placenta previa

\begin{tabular}{|c|c|c|c|c|c|c|c|c|c|c|c|c|c|c|}
\hline \multirow[t]{2}{*}{ Variables } & \multirow{2}{*}{$\begin{array}{l}\text { Low- } \\
\text { lying } \\
(\mathrm{n}= \\
466)\end{array}$} & \multirow{2}{*}{$\begin{array}{l}\text { Marginal } \\
(n= \\
1233)\end{array}$} & \multirow{2}{*}{$\begin{array}{l}\text { Partial } \\
(n= \\
140)\end{array}$} & \multirow{2}{*}{$\begin{array}{l}\text { Complete } \\
(n= \\
2651)\end{array}$} & \multicolumn{5}{|c|}{ Low-lying PP as reference } & \multicolumn{5}{|c|}{ Marginal PP as reference } \\
\hline & & & & & $\begin{array}{l}\text { Marginal } \\
\text { aOR }\end{array}$ & $\begin{array}{l}95 \% \\
\mathrm{Cl}\end{array}$ & $\begin{array}{l}\text { Partial } \\
\text { aOR }\end{array}$ & $\begin{array}{l}95 \% \\
\mathrm{Cl}\end{array}$ & $\begin{array}{l}\text { Complete } \\
\text { aOR }\end{array}$ & $\begin{array}{l}95 \% \\
\mathrm{Cl}\end{array}$ & $\begin{array}{l}\text { Low } \\
\text { aOR }\end{array}$ & $\begin{array}{l}95 \% \\
\mathrm{Cl}\end{array}$ & $\begin{array}{l}\text { Partial } \\
\text { aOR }\end{array}$ & $\begin{array}{l}95 \% \\
\mathrm{Cl}\end{array}$ \\
\hline $\begin{array}{l}\text { Apgar } \\
\text { score } \\
1 \text { min } \leq \\
7\end{array}$ & $\begin{array}{l}59 \\
(12.7 \%)\end{array}$ & $\begin{array}{l}203 \\
(16.5 \%)\end{array}$ & $\begin{array}{l}30 \\
(21.4 \%)\end{array}$ & $\begin{array}{l}626 \\
(23.6 \%)\end{array}$ & 0.89 & $\begin{array}{l}0.62- \\
1.27\end{array}$ & 0.8 & $\begin{array}{l}0.46- \\
1.41\end{array}$ & 1.33 & $\begin{array}{l}0.96- \\
1.84\end{array}$ & 1.13 & $\begin{array}{l}0.79- \\
1.62\end{array}$ & 0.89 & $\begin{array}{l}0.54- \\
1.46\end{array}$ \\
\hline $\begin{array}{l}5 \min \leq \\
7\end{array}$ & $\begin{array}{l}22 \\
(4.7 \%)\end{array}$ & $\begin{array}{l}70 \\
(5.7 \%)\end{array}$ & $\begin{array}{l}13 \\
(9.3 \%)\end{array}$ & $\begin{array}{l}163 \\
(6.1 \%)\end{array}$ & 0.8 & $\begin{array}{l}0.44- \\
1.45\end{array}$ & 0.88 & $\begin{array}{l}0.38- \\
2.06\end{array}$ & 1.2 & $\begin{array}{l}0.68- \\
2.12\end{array}$ & 1.28 & $\begin{array}{l}0.71- \\
2.3\end{array}$ & 1.07 & $\begin{array}{l}0.52- \\
2.19\end{array}$ \\
\hline $\begin{array}{l}\text { Preterm } \\
\text { labor }\end{array}$ & $\begin{array}{l}111 \\
(23.8 \%)\end{array}$ & $\begin{array}{l}543 \\
(44 \%)\end{array}$ & $\begin{array}{l}77 \\
(55 \%)\end{array}$ & $\begin{array}{l}1695 \\
(63.9 \%)\end{array}$ & 2.37 & $\begin{array}{l}1.86- \\
3.03\end{array}$ & 3.62 & $\begin{array}{l}2.42- \\
5.41\end{array}$ & 5.03 & $\begin{array}{l}3.98- \\
6.36\end{array}$ & 0.42 & $\begin{array}{l}0.33- \\
0.53\end{array}$ & 1.53 & $\begin{array}{l}1.07- \\
2.2\end{array}$ \\
\hline $\begin{array}{l}\text { Neonatal } \\
\text { death }\end{array}$ & $\begin{array}{l}3 \\
(0.6 \%)\end{array}$ & $7(0.6 \%)$ & $\begin{array}{l}3 \\
(2.1 \%)\end{array}$ & $16(0.6 \%)$ & 0.95 & $\begin{array}{l}0.22- \\
4.17\end{array}$ & 3.68 & $\begin{array}{l}0.59- \\
23.04\end{array}$ & 2.27 & $\begin{array}{l}0.51- \\
10.13\end{array}$ & 1.34 & $\begin{array}{l}0.3- \\
5.9\end{array}$ & 3.95 & $\begin{array}{l}0.88- \\
17.72\end{array}$ \\
\hline NICU & $\begin{array}{l}46 \\
(9.9 \%)\end{array}$ & $\begin{array}{l}307 \\
(24.9 \%)\end{array}$ & $\begin{array}{l}46 \\
(32.9 \%)\end{array}$ & $\begin{array}{l}725 \\
(27.3 \%)\end{array}$ & 2.6 & $\begin{array}{l}1.78- \\
3.8\end{array}$ & 2.6 & $\begin{array}{l}1.79- \\
3.79\end{array}$ & 2.49 & $\begin{array}{l}1.73- \\
3.57\end{array}$ & 0.39 & $\begin{array}{l}0.26- \\
0.56\end{array}$ & 0.99 & $\begin{array}{l}0.64- \\
1.54\end{array}$ \\
\hline $\begin{array}{l}\text { Birth } \\
\text { weight }< \\
2500 \mathrm{~g}\end{array}$ & $\begin{array}{l}64 \\
(13.7 \%)\end{array}$ & $\begin{array}{l}345 \\
(28 \%)\end{array}$ & $\begin{array}{l}60 \\
(42.9 \%)\end{array}$ & $\begin{array}{l}856 \\
(32.3 \%)\end{array}$ & 2.3 & $\begin{array}{l}1.71- \\
3.09\end{array}$ & 4.46 & $\begin{array}{l}2.89- \\
6.88\end{array}$ & 2.94 & $\begin{array}{l}2.21- \\
3.91\end{array}$ & 0.44 & $\begin{array}{l}0.32- \\
0.59\end{array}$ & 1.95 & $\begin{array}{l}1.35- \\
2.8\end{array}$ \\
\hline
\end{tabular}

PP: placenta previa; NICU: neonatal intensive care unit; Cl: confidence interval; aOR: adjusted odds ratio 


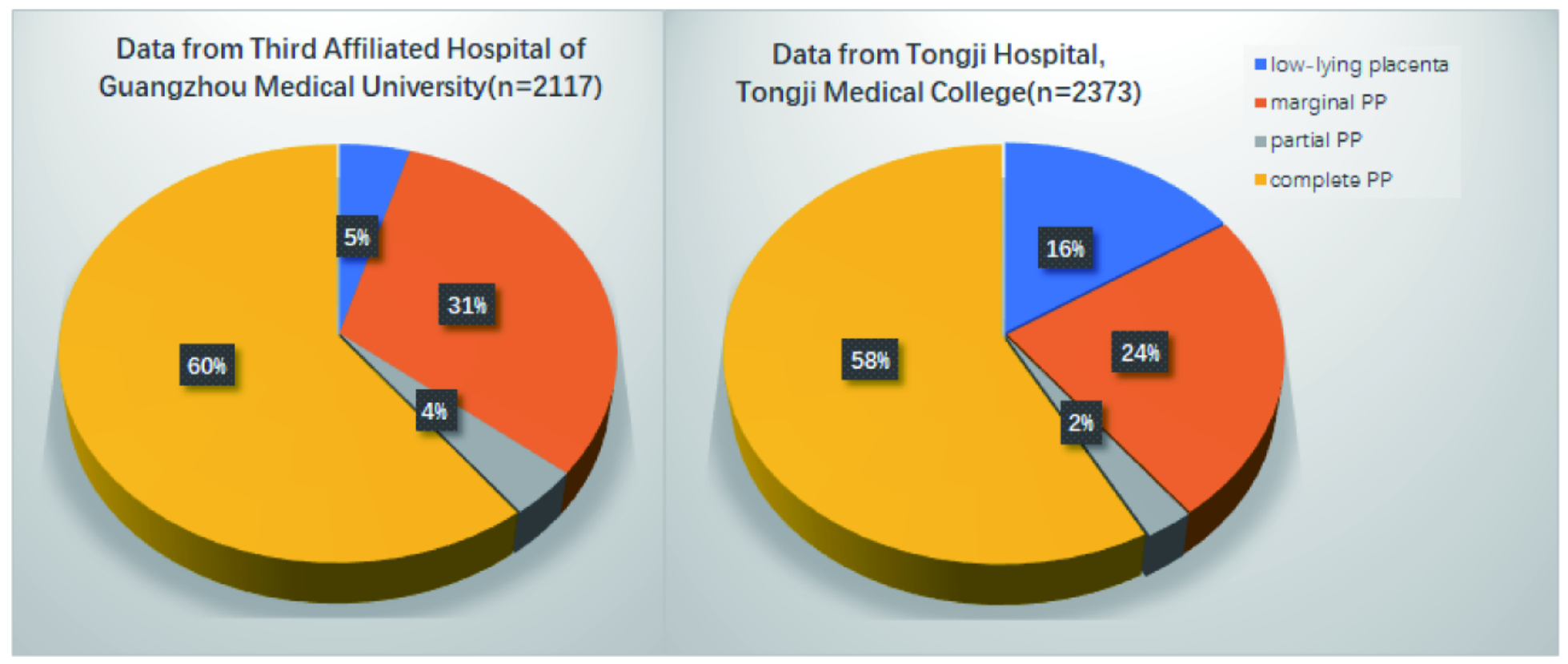

Figure 1

The composition ratios of different types of placenta previa in the two hospitals

\section{Supplementary Files}

This is a list of supplementary files associated with this preprint. Click to download.

- SupplementTables1.docx

- SupplementTableS2.docx

- SupplementTableS3.docx

- SupplementTableS4.docx

- SupplementTables5.docx

- SupplementTableS6.docx 